\title{
FAKTOR YANG MEMPENGARUHI IMPLEMENTASI KEBIJAKAN MITIGASI BENCANA GEMPA DI KECAMATAN BANDAR BARU KABUPATEN PIDIE JAYA
}

\author{
The Factors Related to The Implementation of Earthquake Disaster Mitigation Policy in Bandar Baru \\ Pidie Jaya
}

\author{
Kartika, Azhar Mu'alim, Riski Fadhilah \\ STIKes Medika Nurul Islam \\ Email :kartikabahri85@yahoo.com
}

\begin{abstract}
As a disaster prone area, the government has the obligation and responsibility in anticipating the disaster before or after the disaster, that are by using disaster mitigation, emergency response and rehabilitation reconstruction. Based on the third period, the mitigation is defined as an attempt to minimize the impact of disasters. The second period, emergency respond is defined as the speed in providing assistance during a disaster in a region, and the third period, rehabilitation reconstruction is rebuilding areas damaged. The aim of this research was to know the factors related to the implementation of earthquake disaster mitigation policy in Bandar Baru Pidie Jaya In 2017. The methodology of this research was analytic research by using cross sectional design. The population of this research was all sub-district officers in Bandar Baru Pidie Jaya that consisted of 51 people by using the total sampling technique. The result of this reseach based on 51 respondents was found that the sosialization in the majority of the implementation of mitigation policy of the earthquake disaster was 31 respondents $(96,9 \%)$. The results showed there was a monitoring effect with $p$ value $(0,000)$ and mapping with $p$ value $(0,009)$ on the implementation of earthquake disaster mitigation policy in Bandar Baru District, Pidie Jaya Regency. Where monitoring has a dominant influence compared to mapping factors. it is suggested that sub-district officers increase the implementation of earthquake disaster mitigation policy.
\end{abstract}

Keywords: Mitigation Policy Implementation, Socialization, Monitoring, Mapping

\begin{abstract}
Abstrak
Sebagai daerah rawan bencana, pemerintah mempunyai kewajiban dan tanggung jawab dalam mengantisipasi terjadinya bencana sebelum atau setelah terjadinya bencana yakni mitigasi bencana, tanggap darurat dan rehabilitasi rekonstruksi. Dari ketiga tahapan periode tersebut mitigasi diartikan sebagai upaya untuk meminimalkan dampak yang ditimbulkan oleh bencana. Kedua periode tanggap darurat diartikan sebagai kecepatan dalam pemberian bantuan saat terjadi bencana di suatu wilayah. Tujuan Penelitian: Untuk mengetahui faktorfaktor yang berhubungan dengan implementasi kebijakan mitigasi bencana gempa bumi Di Kecamatan Bandar Baru Kabupaten Pidie Jaya 2017. Metodologi Penelitian: bersifat Analitik dengan desain Cross Sectional. Populasi dalam penelitian adalah semua petugas kantor camat di Kecamatan Bandar Baru Kabupaten Pidie Jaya berjumlah 51 orang dengan teknik pengambilan sampel menggunakan total sampling. Analisis data yang digunakan adalah regresi logistik berganda. Hasil Penelitian: yang diperoleh dari 51 responden adalah Sosialisasi yang ada mayoritas implementasi kebijakan mitigasi bencana gempa bumi ada yaitu sebanyak 31 responden $(96,9 \%)$. Hasil uji multivariat didapatkan Hasil penelitian menunjukkan terdapat pengaruh pemantauan dengan nilai $\mathrm{p}(0,000)$ dan pemetaan dengan nilai $\mathrm{p}(0,009)$ terhadap implementasi kebijakan mitigasi bencana gempa bumi Di Kecamatan Bandar Baru Kabupaten Pidie Jaya. Dimana Pemantauan memiliki pengaruh yang dominan dibandingkan dengan faktor pemetaan. Disarankan kepada petugas kantor camat agar meningkatkan implementasi kebijakan mitigasi bencana gempa bumi.
\end{abstract}

Kata kunci : Implementasi Kebijakan Mitigasi, Sosialisasi, Pemantauan, Pemetaan 


\section{PENDAHULUAN}

Indonesia merupakan daerah rawan bencana, ditandai dengan peristiwa bencana yang melanda di berbagai wilayah. Bencana merupakan suatu kejadian yang tidak dapat dilepaskan dengan kehidupan manusia, baik sebagai individu maupun masyarakat. Bencana dapat disebabkan oleh faktor alam (gempa bumi, tsunami, banjir, letusan gunung api, tanah longsor, angin ribut) dan faktor non alam seperti akibat kegagalan teknologi dan ulah manusia. (Henita, 2014). Bencana gempa dan tsunami pernah terjadi pada tahun 1797, 1891, 1907 dan 2004. Kejadian tsunami 26 Desember 2004 mengakibatkan 126.915 jiwa meninggal, 37.063 jiwa hilang (TDRMC, 2011)

Bencana alam tersebut membuat Pemerintah sebagai penyelenggaraan negara mengeluarkan Undang-Undang no 24 tahun 2007 mengenai penanggulangan bencana. Dalam pasal 5 UndangUndang no 24 tahun 2007 tentang Penanggulangan Bencana disebutkan bahwa penyelenggaraan penanggulangan bencana merupakan tanggungjawab Pemerintah dan Pemerintah Daerah (Triutomo, 2011)

Menurut penelitian Fakhriyani (2011) dengan judul "Implementasi Kebijakan Mitigasi Bencana Gempa dan Tsunami" didapatkan hasil bahwa Pemerintah Kota Padang dalam melaksanakan implementasi kebijakan mitigasi bencana baik struktur dan non struktur masih menghadapi banyak kendala. Dalam hal ini Bapak Wali Kota Padang yaitu Fauzi Bahar yang sadar terhadap kekhawatiran dan kecemasan warganya untuk menghadapi bencana telah melakukan upaya dengan membangun shelter dan sosialisasi sadar bencana. Namun dalam pelaksanaannya mitigasi bencana membutuhkan dana dan pelaksana yang tidak hanya berasal dari personil pemerintah yaitu BPBD tetapi juga NGO dan LSM yang sadar bencana.

Khusus dalam hal bencana yang disebabkan oleh gempa bumi, misalnya, sebagai gambaran hasil penelitian dan kajian beberapa pakar, menunjukkan bahwa selama 25 tahun kejadian gempa di Indonesia, korban bencana lebih diakibatkan oleh kerusakan bangunan rumah sederhana seperti jatuhnya atap, runtuhnya kolom, hancurnya dinding, dan lain-lain. Hal ini menunjukkan bahwa upaya mitigasi bencana gempa bumi melalui pengembangan disain rumah tahan gempa sampai saat ini belum sepenuhnya berhasil (Bappenas, 2009).

Gempa bumi memang sulit diprediksi kapan akan terjadi. Yang bisa lakukan adalah dengan mengetahui indikasi sebelum kejadian gempa terjadi. Indikasi ini dapat diketahui melalui sistem peringatan dini "early warning sistem". Melalui indikasi ini, paling tidak telah mempersiapkan diri untuk menghadapi kemungkinan terburuknya. Dengan mengetahui indikasinya pula akan bijak menentukan bagaimana cara menghadapinya (Bukhari, 2014).

Sebagai daerah rawan bencana, pemerintah Indonesia mempunyai kewajiban dan tanggung jawab dalam mengantisipasi terjadinya bencana sebelum atau setelah terjadinya bencana yakni mitigasi bencana, tanggap darurat dan rehabilitasi rekonstruksi. Dari ketiga tahapan periode tersebut mitigasi diartikan sebagai upaya untuk meminimalkan dampak yang ditimbulkan oleh bencana. Kedua periode tanggap darurat diartikan sebagai kecepatan dalam pemberian bantuan saat terjadi bencana di suatu wilayah. Ketiga rehabilitasirekonstruksi yaitu membangun kembali kawasan yang rusak akibat bencana dengan memperhatikan penataan ruang berbasis mitigasi bencana. Adanya ketentuan untuk melaksanakan mitigasi bencana, sebagai Instansi yang berwenang melaksanakan pengendalian bencana secara nasional adalah Badan Nasional Penanggulangan Bencana (BNPB). BNPB berwenang merumuskan konsep kebijakan penanggulangan bencana nasional, memantau, dan mengevaluasi dalam penyelenggaraan penanggulangan bencana (Fakhriyani, 2011).

Pemerintah sebagai pihak yang paling bertanggungjawab dalam hal ini harus lebih aktif. Upaya pemerintah dalam menanggulangi korban bencana gempa bumi dapat dilakukan melalui tanggap darurat, mitigasi bencana, dan rekonstruksi, baik rekonstruksi bangunan maupun rekontruksi pkisis bagi korban bencana gempa bumi. Namun permasalahan gempa bumi tidak hanya masalah 
pemerintah saja, tapi juga masalah semua individu. Maka pemahaman tentang gempa bumi mutlak diperlukan bagi siapa saja agar korban dapat diminimalisasi. Selama ini kesiapan masyarakat terhadap bencana gempa bumi sangat minim. (Andi, 2013).

Pada tanggal 7 Desember 2016 telah terjadi gempa bumi dengan kekuatan 6.5 Mw yang epicenternya berada di $5.281 \mathrm{oN}$ dan 96.108oE (Sumber USGS) dengan kedalaman pusat gempabumi diperkirakan berada di sekitar $8.7 \mathrm{~km}$. Gempa bumi tersebut dirasakan hingga ke Banda Aceh, Medan dan beberapa kota lainnya di sebelah utara Pulau Sumatera. Sampai dengan sore tanggal 7 Desember 2016, jumlah korban jiwa tercatat 102 meninggal dunia, 650 jiwa luka berat/ringan (Umar, 2016). Penelitian ini bertujuan mengetahui faktorfaktor yang berhubungan dengan implementasi kebijakan mitigasi bencana gempa bumi di Kecamatan Bandar Baru Kabupaten Pidie Jaya 2017.

\section{BAHAN DAN METODE}

Penelitian ini menggunakan metode penelitian analitik dengan pendekatan crossectional. Variabel independen dalam peenlitian ini meliputi pemetaan, pemantauan dan sosialisasidan variable dependen dalam penelitian ini adalah implementasi kebijakan mitigasi bencana Gempa Bumi. Populasi dan sampel dalam penelitian ini adalah karyawan yang melakukan peninjauan di Kecamatan Bandar Baru Kabupaten Pidie Jaya Sebanyak 51 orang. Dilaksanakan di Kantor Kecamatan Bandar Baru Kabupaten Pidie Jaya pada Bulan Oktober. Analisis data yang digunakan adalah uji regresi logistic berganda.

\section{HASIL DAN PEMBAHASAN}

\section{Analisis Univariat}

Berikut ini distribusi frekuensi variabel penelitian terhadap Kebijakan Mitigasi Bencana Gempa Bumi Di Kecamatan Bandar Baru Kabupaten Pidie Jaya.
Tabel 1. Distribusi frekuensi variabel penelitian terhadap Kebijakan Mitigasi Bencana Gempa Bumi Di Kecamatan Bandar Baru Kabupaten Pidie Jaya.

\begin{tabular}{lcc}
\hline Variabel & $\mathbf{n}$ & $\mathbf{0}$ \\
\hline Implementasi & & \\
$\quad$ Ya & 33 & 64,7 \\
Tidak & 18 & 35,3 \\
Sosialisasi & & \\
$\quad$ Ada & 32 & 62,7 \\
$\quad$ Tidak & 19 & 37,3 \\
Pemantauan & & \\
$\quad$ Ada & 32 & 62,7 \\
$\quad$ Tidak & 19 & 37,3 \\
Pemetaan & & \\
$\quad$ Ada & 30 & 58,8 \\
$\quad$ Tidak & 12 & 41,2 \\
\hline Jumlah & $\mathbf{5 1}$ & $\mathbf{1 0 0}$ \\
\hline
\end{tabular}

Berdasarkan Tabel 1 menunjukkan bahwa implementasi kebijakan mitigasi bencana gempa bumi berada pada kategori ada yaitu sebanyak 33 responden $(64,7 \%)$. Sosialisasi yang dilakukan pada bencana gempa bumi berada pada kategori ada yaitu sebanyak 32 responden (62,7\%). Pemantauan yang dilakukan pada bencana gempa bumi berada pada kategori ada yaitu sebanyak 32 responden (62,7\%). Pemetaan yang dilakukan pada bencana gempa bumi berada pada kategori ada yaitu sebanyak 30 responden $(58,8 \%)$.

\section{Analisis Bivariat}

Faktor yang mempengaruhi Implementasi Kebijakan Mitigasi Bencana Gempa Bumi dapat dilihat pada tabel 2 berikut.

Tabel 2. Faktor yang mempengaruhi Implementasi Kebijakan Mitigasi Bencana Gempa Bumi Di Kecamatan Bandar Baru Kabupaten Pidie Jaya

\begin{tabular}{lcc}
\hline Implementasi & B & p. \\
Kebijakan Mitigasi & & \\
\hline Constanta & 0,456 & \\
Pemantauan & 0,595 & 0,000 \\
Pemetaan & 0,302 & 0,009 \\
\hline
\end{tabular}


Mitigasi bencana yang merupakan bagian dari manajemen penanganan bencana, menjadi salah satu tugas Pemerintah Pusat dan Pemerintah Daerah dalam rangka pemberian rasa aman dan perlindungan dari ancaman bencana yang mungkin dapat terjadi. Ada empat hal penting dalam mitigasi bencana, antara lain tersedia informasi dan peta kawasan rawan bencana untuk tiap jenis bencana; sosialisasi untuk meningkatkan pemahaman dan kesadaran masyarakat dalam menghadapi bencana, karena bermukim di daerah rawan bencana; mengetahui apa yang perlu dilakukan dan dihindari, serta mengetahui cara penyelamatan diri jika bencana timbul, dan pengaturan dan penataan kawasan rawan bencana untuk mengurangi ancaman bencana (Permenkes RI, 2006).

Hasil penelitian menunjukkan ada pengaruh pemantauan terhadap implementasi kebijakan mitigasi bencana gempa bumi ini dikarenakan dengan adanya pemantauan, petugas bisa mengetahui tingkat kerusakan dan kebutuhan masyarakat pasca gempa bumi sehingga petugas bisa memberikan bantuan yang dibutuhkan oleh masyarakat. Dengan mengetahui tingkat kerawanan secara dini, maka dapat dilakukan antisipasi jika sewaktu-waktu terjadi bencana, sehingga akan dengan mudah melakukan penyelamatan. Pemantauan di daerah vital dan strategis secara jasa dan ekonomi dilakukan di beberapa kawasan rawan bencana (Permenkes RI, 2006). Menurut penelitian Indyah (2015) dengan judul Implementasi Kebijakanan Penanggulangan Bencana di Jakarta didapatkan ada hubungan yang signifikan antara pemantauan dengan implementasi kebijakan penanggulangan bencana dengan hasil uji statistik $P$ value yaitu 0,006 .

Pemantauan berfungsi dalam memastikan bahwa setiap personal yang bertanggung jawab bisa melaksanakan segala tugas yang diembannya. Pemantaua ini dilakukan sesuai dengan system operasional dan prosedur yang berlaku, sehingga dapat dianalisis setiap kesalahan maupun penyimpangan yang terjadi, yang kemudian diberikan tindakan koreksi ataupun arahan.

Hasil penelitian menunjukkan bahwa ada pengaruh pemetaan dengan implementasi kebijakan mitigasi bencana gempa bumi sehingga dapat disimpulkan bahwa pemetaan sangat penting untuk melihat tingkat kerawanan bencana dan daerah mana saja yang mengalami bencana serta dengan adanya pemetaan masyarakat bisa melihat lokasi yang rawan gempa bumi.

Langkah pertama dalam strategi mitigasi ialah melakukan pemetaan daerah rawan bencana. Pada saat ini berbagai sektor telah mengembangkan peta rawan bencana. Dengan nilai $\mathrm{R}^{2}$ 0,638 yang artinya nahwa faktor pemantauan dan pemetaan mempengaruhi implementasi kebijakan mitigasi bencana gempa bumi Di Kecamatan Bandar Baru Kabupaten Pidie Jaya sebesar 63,8\%.

Hasil penelitian menunjukkan terdapat pengaruh pemantauan dengan nilai $\mathrm{p}(0,000)$ dan pemetaan dengan nilai $\mathrm{p}(0,009)$ terhadap implementasi kebijakan mitigasi bencana gempa bumi Di Kecamatan Bandar Baru Kabupaten Pidie Jaya. Dimana Pemantauan memiliki pengaruh yang dominan dibandingkan dengan faktor pemetaan.

Peta rawan bencana tersebut sangat berguna bagi pengambil keputusan terutama dalam antisipasi kejadian bencana alam. Meskipun demikian sampai saat ini penggunaan peta ini belum dioptimalkan ini dikarenakan Peta bencana yang dibuat memakai peta dasar yang berbeda beda sehingga menyulitkan dalam proses integrasinya (Permenkes RI, 2006). Menurut penelitian Fakhriyani (2011) dengan judul Implementasi Kebijakan Mitigasi Bencana Gempa Dan Tsunami di Padang didapatkan ada hubungan yang signifikan antara pemetaan rawan gempa bumi dengan implementasi kebijakan mitigasi bencana gempa bumi dan tsunami dengan hasil uji statistik $P$ value yaitu 0,003 .

\section{KESIMPULAN}

Implementasi kebijakan mitigasi bencana gempa bumi berada pada kategori terdapat implemenyasi yaitu sebesar 64,7\%. Terdapat pengaruh pemantauan dan pemetaan dengan implementasi kebijakan mitigasi bencana gempa bumi. Pemantauan merupakan faktor dominan mempengaruhi implementasi kebijakan mitigasi bencana gempa bumi. Faktor pemantauan dan 
pemetaan mempengaruhi implementasi kebijakan mitigasi bencana gempa bumi Di Kecamatan Bandar Baru Kabupaten Pidie Jaya sebesar 63,8\%.

Bagi institusi diharapkan dapat dijadikan sebagai data dasar untuk penelitian selanjutnya dan sebagai bahan informasi bagi pengembangan ilmu penelitian lebih lanjut terutama yang berkaitan dengan faktor-faktor yang berhubungan dengan implementasi kebijakan mitigasi bencana gempa bumi. Bagi peneliti lain diharapkan penelitian ini dapat dimanfaatkan dan dijadikan sebagai bahan referensi untuk pustaka dan hasil penelitian ini dapat dijadikan dasar dalam melakukan penelitian lebih lanjut.

\section{DAFTAR PUSTAKA}

Andi. (2013). Implementasi Pendidikan Mitigasi Bencana Gempa Bumi. Surakarta: UM

Bappenas. (2009). Rencana Aksi Nasional Pengurangan Risiko Bencana. Diakses dari https://www.bappenas.go.id/files/5113/502

2/6066/versi-bahasaindonesia_20081122175120_826_0.pdf

Bukhari, Mudatsir, Sri A. (2014). Hubungan Sikap tentang Regulasi, Pengetahuan dan Sikap Perawat terhadap Kesiapgaan Bencana Gempa Bumi di Badan Layanan Umum Daerah Rumah Sakit Ibu dan Anak Pemerintah Aceh. Jurnal: Jurnal Ilmu Kebencaan Vol I no. 2 Hal 37-46 diakses dari http://www.jurnal.unsyiah.ac.id/JIKA/articl e/view/5601/4633

Fakhriyani. (2011). Implementasi Kebijakan Mitigasi Bencana Gempa Dan Tsunami. Padang: Skripsi Fakultas Ilmu Sosial dan Ilmu Politik Universitas Andalas diakses dari http:/ / repository.unand.ac.id/17038/1/IMPL EMENTASI_KEBIJAKAN_MITIGASI_BENCA NA.pdf

Indyah H. (2015). Implementasi Kebijakan Penanggulangan Bencana (Studi Deskriptif tentang Penanggulangan Bencana Letudan Gunung Kelud di Kecamtan Ngancar Kabupaten Kediri). Jurnal: Kebujakan dan Manajemen Publik Vol 3 Nomer 2 diakses dari http://journal.unair.ac.id/downloadfullpapers-kmpbdf7cee63afull.pdf

Pemernekes RI. (2006). Pedoman Umum Mitigasi Bencana. Jakarta: Mentri dalam Negeri diakses dari http://www.gitews.org/tsunamikit/en/E6/further_resources/national_level/ peraturan_menteri/Permendagri\%20332006_Pedoman\%20Umum\%20Mitigasi\%20Ben cana.pdf

Rahmayanti, Henita. 2014. Adaptasi Masyarakat Kota Rawan Bencana, Tinjauan Konsep Pemahaman, Persepsi, dan Kesiapan Mitigasi dalam Perubahan Tata Ruang. Jakarta : Universitas Indonesia diakses dari https://anzdoc.com/-henita-rahmayantidisain-sampul-henita-rahmayanti-midorihi.html

TDRMC. (2011). Atlas peta risiko bencana aceh. TDRMC, Banda Aceh

Triutomo, S. (2011). Panduan Perencanaan Kontinjensi Menghadapi Bencana. Jakarta : Badan Nasional Penanggulangan Bencana

Umar. (2016). Kaji Cepat Universitas Syiah Kuala Terhadap Gempa Bumi 6.5MW Tanggal 7 Desember 2016 Di Sekitar Pidie Jaya-Aceh. Banda Aceh: Unsyiah diakses dari http://gempa.unsyiah.ac.id/wpcontent/uploads/2016/12/Hasil-Kaji-CepatUnsyiah-Gempa-Pijay-07-Des-2016 